\title{
Influence of direct to consumer pharmaceutical advertising and patients' requests on prescribing decisions: two site cross sectional survey
}

\author{
Barbara Mintzes, Morris L Barer, Richard L Kravitz, Arminée Kazanjian, Ken Bassett, Joel Lexchin,
} Robert G Evans, Richard Pan, Stephen A Marion

Centre for Health Services and Policy Research, University of British Columbia, Vancouver BC, Canada V6T $1 Z 3$ Barbara Mintzes graduate researcher Morris L Barer professor

Arminée Kazanjian acting director

Ken Bassett senior medical consultant

Robert G Evans professor

Department of Health Care and Epidemiology, University of British Columbia, Canada Stephen A Marion associate professor Center for Health Services Research in Primary Care, University of California, Davis, Sacramento CA, 95817 USA

Richard L Kravitz professor and director School of Health Policy and

Management, York

University, Toronto,

Ontario, Canada

M3J 1P3

Joel Lexchin

associate professor

PC-AWARE, Center for Health Services

Research in

Primary Care

University of

California Davis

Medical Centre,

Davis

Richard Pan executive director

Correspondence to:

B Mintzes

bmintzes@

chspr.ubc.ca

BMJ 2002;324:278-9
Only the United States and New Zealand allow advertising of prescription drugs directed at patients. US spending on such advertising grew rapidly during the 1990 s, reaching $\$ 2.47 \mathrm{bn}(£ 1650 \mathrm{~m})$ in $2000 .{ }^{1}$ The dramatic increase in investment by the US pharmaceutical industry is evidence of an expected effect on sales. On the rationale that such advertising provides important information to consumers and patients who may benefit from advertised products, pharmaceutical manufacturers have campaigned in the European Union $^{2}$ and Canada ${ }^{3}$ for the relaxing of current regulatory restrictions. We examined the relation between direct to consumer advertising and patients' requests for prescriptions and the relation between patients' requests and prescribing decisions.

\section{Participants, methods, and results}

We carried out a cross sectional survey of a cluster sample of primary care patients in Sacramento, California, from March to June 2001 and in Vancouver, British Columbia, from June to August 2000. We used questionnaires to determine the frequency of patients' requests for prescriptions and of prescriptions resulting from requests. Seventy eight physicians participated in the study, 40 in Vancouver (all family physicians) and 38 in Sacramento (14 general internists and 24 family physicians).

Patients were all 18 years and over, spoke English, and provided informed consent. The unit of analysis was a matched set of patient-physician questionnaires covering a single consultation. We estimated adjusted odds ratios using a generalised estimation equation. We classified drugs as advertised to consumers if they were among the 50 drugs with the highest US advertising budgets ${ }^{4}$ or were described as advertised to consumers in Canadian media reports ${ }^{5}$ in 1999-2000, or both.

Sixty one per cent of patients attending physicians' offices on preset study days participated (1431 total; 683 in Sacramento and 748 in Vancouver). Patients in the two cities had similar demographic characteristics, socioeconomic status, and attitudes toward the doctorpatient relationship. In both settings, income was higher than average, and $80 \%$ were of European descent.

Patients requested prescriptions in $12 \%$ of surveyed visits. Of these requests, $42 \%$ were for products advertised to consumers. The table provides details of factors associated with requests. Physicians prescribed the requested drugs to $9 \%$ (128) of patients and requested advertised drugs to $4 \%$ (55) of patients. The prescribing rate was similar for advertised and non-advertised drugs (about 74\%).

After we controlled for health status, demographics, socioeconomic status, drug payment, and physicians' sex, specialty, and years of practice we examined the influence of requests on the probability that a patient received a new prescription. Patients who

Details from questionnaires given to patients and physicians regarding requests for prescription drugs

\begin{tabular}{|c|c|c|c|c|}
\hline \multirow{2}{*}{$\begin{array}{l}\text { Factors associated with } \\
\text { requests }\end{array}$} & \multicolumn{2}{|c|}{ Patients who requested $\geqslant 1$ drug (any drug) } & \multicolumn{2}{|c|}{ Patients who requested $\geqslant 1$ direct advertised drug } \\
\hline & No (\%) of patients & Odds ratio* $(95 \% \mathrm{Cl})$ & No $(\%)$ of patients & Odds ratio* $(95 \% \mathrm{CI})$ \\
\hline \multicolumn{5}{|c|}{ Does the patient believe a new prescription was needed? } \\
\hline Yes & $75 / 264(28.4)$ & $4.2(2.9$ to 6.1$)$ & $39 / 264(14.8)$ & 5.5 (3.2 to 9.5$)$ \\
\hline No & 100/1167 (8.1) & & $35 / 1167(3.0)$ & \\
\hline \multicolumn{5}{|c|}{ Has the patient requested drugs before? } \\
\hline Yes & $67 / 348(19.3)$ & $2.0(1.5$ to 2.8$)$ & $32 / 348(9.2)$ & $2.3(1.4$ to 3.7$)$ \\
\hline No & $108 / 1083(10.0)$ & & $52 / 1083(4.8)$ & \\
\hline \multicolumn{5}{|c|}{ Does the patient have a condition treatable by an advertised drug? } \\
\hline Yes & $67 / 365(18.4)$ & $1.9(1.4$ to 2.8$)$ & $38 / 365(10.4)$ & $3.1(2.0$ to 4.9$)$ \\
\hline No & $108 / 1066(10.1)$ & & $36 / 1066(3.4)$ & \\
\hline \multicolumn{5}{|c|}{ Does the patient use advertising as an information source? } \\
\hline Yes & $17 / 84(20.2)$ & $1.6(0.9$ to 2.8$)$ & $13 / 84(15.5)$ & $3.2(1.8$ to 6.0$)$ \\
\hline No & $158 / 1347(11.7)$ & & $61 / 1347(4.5)$ & \\
\hline \multicolumn{5}{|c|}{ Does the patient recall having seen adverts for at least three of six listed drugs? } \\
\hline Yes & $123 / 800(15.4)$ & $1.7(1.2$ to 2.4$)$ & $56 / 800(7.0)$ & $2.0(1.1$ to 3.6$)$ \\
\hline No & $52 / 631(8.2)$ & & $18 / 631(2.9)$ & \\
\hline \multicolumn{5}{|c|}{ Does the patient recall seeing more than five prescription drugs advertised in the past year? } \\
\hline Yes & $111 / 822(13.5)$ & $1.3(0.9$ to 1.9$)$ & $54 / 822(6.6)$ & $2.2(1.3$ to 3.8$)$ \\
\hline No & $64 / 609(10.5)$ & & $20 / 609(3.3)$ & \\
\hline Total requests & $175 / 1431(12.2)$ & & $74 / 1431(5.2)$ & \\
\hline Requested drug prescribed & $128 / 1431(8.9)$ & & $55 / 1431(3.8)$ & \\
\hline
\end{tabular}

*0dds ratios adjusted for age, sex, health status, income, drug payment, and cluster sampling. 
requested a prescription (for advertised and nonadvertised drugs) were more likely to receive one (139/175 v 329/1256, odds ratio 8.7, 95\% confidence interval 5.4 to 14.2 ).

We asked physicians: "If you were treating another similar patient with the same condition, would you prescribe this drug?" An answer of "very likely" indicated confidence in choice and "possibly" or "unlikely" indicated some degree of ambivalence. Physicians were ambivalent about the choice of treatment in around $40 \%$ of cases when patients requested drugs (advertised and non-advertised, 62/143 v 62/500, 5.4, 3.5 to 8.5 ) and about half the cases when patients had requested advertised drugs (30/60 $v 62 / 500,7.1,4.0$ to 12.6) compared with $12 \%$ for drugs not requested by patients.

\section{Comment}

Patients' requests for medicines are a powerful driver of prescribing decisions. In most cases physicians prescribed requested medicines but were often ambivalent about the choice of treatment. If physicians prescribe requested drugs despite personal reservations, sales may increase but appropriateness of prescribing may suffer. Concerns about the value of opening up the regulatory environment to permit direct to consumer advertising in the $\mathrm{EU}$ and Canada seem well justified.

We thank Robert Woollard for assistance with recruitment of physicians in Vancouver and the physician questionnaire; the research assistants who administered the survey: Amit Ahuja, Danielle Lapointe, Michael Tsang, Christine Choi, Vanphen Chanthalangsy, Min H Ku, Laura Shively, Erica Stranger, Nicollet Knopf, Bryan Faulstich, Karry Nagai, and Meridith Cobari;
Sara Lu Vorhes and Valerie Olson for research coordination in Sacramento; and Nhue L Do and Alicia Mintzes for data entry. Members of a multidisciplinary expert advisory panel assisted with the study design: Wendy Armstrong, Alan Cassels, Jean-Pierre Gregoire, Matthew Hollon, Patricia Kaufert, Joel Lexchin, Bob Nakagawa, Nancy Ostrove, Richard Pollay, and Ingrid Sketris.We also thank all of the physicians and patients who participated in the survey.

Contributors: BM and MLB contributed to all aspects of study planning, design, analysis, and reporting. RLK, AK, and $\mathrm{KB}$ contributed to interpretation of the data, review of drafts the manuscript and, to a lesser extent, study planning, questionnaire design, and data collection. JL and RGE contributed to study design, interpretation, and review of the manuscript. RP contributed to US components of study design and organised and supervised data collection and entry in Sacramento. SAM contributed to the analysis plan and interpretation and to subsequent discusssion of these components of the manuscript $\mathrm{BM}$ and MLB are guarantors.

Funding: Health Transition Fund, Health Canada. Barbara Mintzes also received a PhD training fellowship for this research from the National Health Research and Development Programme (NHRDP) and the Canadian Institutes of Health Research.

Competing interests: None declared.

Like many journals the BMJ derives income from pharmaceutical advertising. Direct to consumer advertising of prescription drugs competes with this channel.

1 IMS Health. US leading products by DTC spend. January 2000-December 2000. Fairfield, CT: IMS Health, 2001. www.imshealth.com/public/ structure/dispcontent/1,2779,1203-1203-143221,00.html (accessed 19 December 2001).

2 Watson R. EC moves towards "direct to consumer" advertising. BMJ 2001;323:184

3 Therapeutic Products Programme. Direct-to-consumer advertising of prescription drugs. Discussion document. Ottawa: Health Canada, 1999

4 Findlay S. Prescription drugs and mass media marketing. Research brief. Washington, DC: National Institute of Health Care Management, 2000. www.nihcm.org (accessed 15 March 2001).

5 Silversides A. Direct-to-consumer prescription drug ads getting bolder Can Med Assoc J 2001;165:462.

(Accepted 14 January 2002)

\section{Two memorable patients \\ Two deaths, two lives}

Some days in general practice are surprising. On a Tuesday morning last June I was due to see Miss Jean Smith at 1020 . She had longstanding angina and recently had worsening breathlessness. We had discussed my referring her to a specialist, but in her old fashioned polite and deferential way she'd said, "It's up to you, doctor, but maybe we could wait." I had known her for many years but had never visited her at home, and I had formed a picture of her as a spinster, living very much alone, supported by a few friends from the church.

At 950 the telephone rang, and a receptionist told me that Jean Smith has been found dead in her bedroom by the police. Could I go and certify the death? I drove down and was greeted by a policewoman. In the lounge sat an elegantly suited grey haired man. "Oh hello, Dr Memel, I am so pleased to meet you. Jean told me so much about you. I came to pick her up for her appointment with you, like I always do, but the front door was bolted .... We are good friends, of course, but I am not the next of kin." A two minute chat, then I went upstairs to confirm that she was dead before returning to my half completed surgery.

An hour later, and Susie came to see me. Her estranged husband, Donald Hill, had died two weeks earlier from a bleeding peptic ulcer, alone in his flat. He had been to see me several times over the previous months, complaining of vomiting and depression. Slowly from him a story of sad alcoholism had emerged, of a lonely divorced man whose only solace and social life was going to the pub.

Susie now told me a very different story. A bubbly lady, she was my patient 10 years ago, before moving on to one of my partners. "Don't you remember how I told you about Donald, how I could not stand to live with him and his drinking?" I did not remember. She told me how she had continued to see him regularly over the years, and still loved him. She was devastated by the way he had died alone. She showed me a newspaper that she had found in his flat. On it was scrawled in different places, "Sicked blood, feel awful," "Must phone Susie," "Passed out, sick again."

I thought about these two patients recently while attending a fascinating conference on narrative based medicine, organised by the BMJ. The anthropologists' presentations emphasised that within the stories of people's lives there are often more than one account-that of the subject, those of other participants, and that of the narrator, with each adding his or her own interpretation. These two patients, who are now dead, told me some things about their lives but did not tell me others. I asked some questions but did not ask others, or did not hear the answers, and I fantasised to fill the gaps. As their general practitioner over many years, I thought that I knew these two patients well, but I realise that I did not.

David Memel general practitioner, Bristol (dmemel@airballoon.cix.co.uk)

We welcome articles up to 600 words on topics such as A memorable patient, A paper that changed my practice, My most unfortunate mistake, or any other piece conveying instruction, pathos, or humour. If possible the article should be supplied on a disk. Permission is needed from the patient or a relative if an identifiable patient is referred to. We also welcome contributions for "Endpieces," consisting of quotations of up to 80 words (but most are considerably shorter) from any source, ancient or modern, which have appealed to the reader. 